\title{
Advance of Electroconductive Hydrogels for Biomedical Applications in Orthopedics
}

\author{
Jian Cao $(\mathbb{D}$, Zhongxing Liu, Limin Zhang, Jinlong Li, Haiming Wang, and Xiuhui Li \\ Department of Orthopedics, Affiliated Hospital of Chifeng University, Chifeng, Inner Mongolia 024000, China \\ Correspondence should be addressed to Jian Cao; caojian2005088@sina.cn
}

Received 2 October 2020; Revised 7 November 2020; Accepted 12 January 2021; Published 23 January 2021

Academic Editor: Lingxue Kong

Copyright ( $) 2021$ Jian Cao et al. This is an open access article distributed under the Creative Commons Attribution License, which permits unrestricted use, distribution, and reproduction in any medium, provided the original work is properly cited.

\begin{abstract}
Electroconductive hydrogels (EHs) are promising composite biomaterials of hydrogels and conductive electroactive polymers, incorporating bionic physicochemical properties of hydrogels and conductivity, electrochemistry, and electrical stimulation (ES) responsiveness of conductive electroactive polymers. The biomedical domain has increasingly seen EHs' application to imitating the biological and electrical properties of human tissues, acclaimed as one of the most effective biomaterials. Bone's complex bioelectrochemical properties and the corresponding stem cell differentiation affected by electrical signal elevate EHs' application value in repairing and treating bone, cartilage, and skeletal muscle. Noteworthily, the latest orthopedic biological applications require broader information of EHs. Except for presenting the classification and synthesis of EHs, this review recapitulates the advance of EHs application to orthopedics in the past five years and discusses the pertinent development tendency and challenge, aiming to provide a reference for EHs application direction and prospect in orthopedic therapy.
\end{abstract}

\section{Introduction}

The past few decades have seen a dramatic increase in the demand for more efficient and complex biomaterials, of which hydrogels began to excel. Hydrogels are porous threedimensional network structures with high water content obtained by physical or chemical cross-linking of hydrophilic polymer chains. Hydrogels incorporate many merits of adjustable physical and chemical properties, the ability to imitate extracellular matrix, injectability, self-healing, biocompatibility, biodegradability, low toxicity, the ability to encapsulate cells, growth factors, and drugs, and others [1]. The current materials for hydrogel manufacturing primarily fall into natural polymers and synthetic polymers. The natural polymers cover fibrin, hyaluronic acid, chitosan, gellan, gelatin, collagen, alginate, and others. In contrast, the synthetic polymers include polylactide (PLA), poly(ethylene glycol) (PEG), poly(vinyl alcohol) (PVA), poly(2-hydroxyethyl methacrylate) (PHEMA), poly(lactic-co-glycolic acetic acid) (PLGA), polycaprolactone (PCL), poly(glycerol sebacate), and polyurethane (PU) [2-6]. Most of these polymers are nonconductive. However, common knowledge proves that the survival of cells, tissues, and organs is inseparable from bioelectrical signals $[7,8]$. Hydrogels in biomedical applications are critical to the generation, conduction, utilization, and conversion of electrical signals [9]. Opportunely, the concept of EHs comes from attempts in the 1990s of scientists to introduce conductive material into hydrogels $[10,11]$. Currently, conductive materials used in hydrogels primarily are conductive polymers, including polyaniline (PAn), polypyrrole (PPy), polythiophene (PTh), poly(phenylene vinylene) ( $\mathrm{PPv})$, their copolymers, and derivatives. Besides, various metal nanoparticles and carbonbased nanoconductive materials like graphene and carbon nanotubes (CNTs) have seen application to hydrogels [12-17]. The addition of various conductive active materials will produce advanced composite material of EHs with controlled conductive phase morphology. In recent years, the clinical medicine domain of electroactive cell and tissue engineering has seen an in-depth development and extensive application of EHs, such as skin, muscle, nerve, heart, bone, and cartilage $[4,18-20]$.

This review first classifies electroconductive hydrogels by composition: (i) conductive polymer hydrogels; (ii) 
conductive metallic nanoparticle hydrogels; (iii) conductive graphene and CNTs hydrogels. Except for the brief introduction of the synthetic methods for the above electroconductive hydrogels, this review emphatically analyzes EHs for biomedical applications in orthopedics, covering EHs as cell culture medium, scaffolds in tissue engineering, delivery application of drugs, or growth factors. To provide a reference for EHs treating orthopedic disorders in the future, this review finally discusses the opportunities and challenges for developing biomedical applications, particularly EHs in orthopedics.

\section{The Classification of EHs}

2.1. Conductive Polymer Hydrogels. $\pi$-Conjugated polymers of PANi, PPv, PPy, polythiophene (PT), poly(3,4-ethylenedioxythiophene) (PEDOT), and others have witnessed an extensive application in EHs [12], seen in Figure 1. The delocalized $\pi$ electrons move freely in their unsaturated main backbone, constructing an electrical pathway for mobile charge carriers [21]. $\pi$-Conjugated polymers are easy to synthesize and process, acclaimed as a class of organic materials with unique electrical and optical properties similar to those of inorganic semiconductors and metals. Also, their electrical properties and biological responsiveness are more stable and controllable than those of other materials, and their long covalent chains provide better mechanical properties for the whole system.

EHs with conductive polymers compatible with other hydrogel substrates have demonstrated excellent biocompatibility and applications in the biomedical domain, seen in Table 1 . Conductive polymers need to combine with ideal supporting materials to cover up their instability and susceptibility to oxidation. Lately, Wang et al. [22] prepared polypyrrole-grafted gelatin-based hydrogels with conductivity, self-healing, and injectability. They first grafted methacrylate anhydride (MA) onto the gelatin to form a double bond functional gelatin (GelMA) through a physical cross-linking network. Then, they grafted PPy to GelMA by reacting with the double bond to form a PPy-GelMA graft (PPy-GelMA). Later, they added iron ions to the PPyGelMA solution to form the hydrogel. Due to reversible ion action, the resulting hydrogels are self-healing and present excellent blood and cellular compatibility. In treating myocardial infarction, the self-adhesive conductive hydrogel patch formed based on the ion-ligand binding between $\mathrm{Fe}^{3+}$ inducing dopamine-gelatin (GelDA) conjugate and dopamine-functionalized DA-PPy could significantly improve myocardial function in combination with the injectable hydrogel [23]. Notably, the monomer or cross-linking agent left in the hydrogel system may be toxic to cells and tissues, and scientists are looking for natural biological cross-linking agents to solve this problem [27]. Besides PPy, PANi is also one of the conductive polymers most widely studied in biomedicine.

Bagheri et al. [27] utilized the biodegradability and fabricability of aniline oligomers to synthesize self-gelling electroactive hydrogels based on chitosan-aniline oligomers/ agarose to deliver drugs in neural tissue engineering. Their team also demonstrated that gelatin's introduction to these EHs significantly promoted motor neuron-like cell differentiation of human olfactory ectomesenchymal stem cells [28]. A hydrogel prepared by simple grafting of gelatin and PANi is also applicable to deliver bone marrow stromal cells (BMSCs), significantly improving the behavior in mice with Parkinson's disease and the neurotrophic factor levels in the substantia nigra [29]. Except for PPy and PANi, complex biomedical purposes keep seeking other conductive polymers. From a conducting polymer complex, poly(3,4-ethylenedioxythiophene): polystyrene sulfonate (PEDOT: PSS) dispersed within a photo-cross-linkable naturally derived hydrogel, gelatin methacryloyl (GelMA), Spencer et al. [31] prepared electroconductive hydrogels with adjustable properties and mechanical flexibility, which supports $\mathrm{C}_{2} \mathrm{C}_{12}$ myoblasts' viability and proliferation. Importantly, PEDOT's monomers are hydrophilic and soluble in water, facilitating biodegradation and elimination. In the study of nerve tissue regeneration, the incorporation of PEDOThyaluronic acid nanoparticles into chitosan/gelatin (Cs/Gel) matrix can improve the electrical and mechanical properties while reducing the porosity, water absorption, and biodegradability, and PC12 cells cultured in scaffolds exhibited a higher expression of synaptic growth genes [32].

2.2. Conductive Metallic Nanoparticle Hydrogels. Strong electrical conductivity in metals inspires an effective way to synthesize EHs by doping metal nanoparticles into the hydrogel matrix. The higher corrosion resistance of gold, silver, platinum, and other precious metals in the physiological environment enhances their utilization in EHs [33]. Regarding their low bioactivity, dose- and time-dependent cytotoxicity, modification, and compounding are applicable to maintain their homeostasis, enhance their interaction with the biological environment, improve their biocompatibility, and prolong their existence in vivo $[34,35]$. Besides their electrical conductivity, these metal nanoparticles present surprising functions and properties, respectively, such as antibacterial property, catalytic, imaging, and drug delivery [36-38].

Conductive metallic nanoparticle hydrogels have demonstrated usefulness in biomedicine, seen in Table 2. For example, Pourjavadi et al. prepared injectable and thermosensitive chitosan $/ \kappa$-carrageenan hydrogel designed with au nanoparticles [39]. They first loaded Au nanoparticles with an average size of $50-70 \mathrm{~nm}$ onto the chitosan surface through a green method to enhance the conductivity. Then, they synthesized injectable and thermosensitive hydrogel through two steps with the effect of radical polymerization and static electricity, the chitosan loaded with Au nanoparticles, $\kappa$-carrageenan, and poly $(\mathrm{N}$-isopropylacrylamide) (PNIPAM). In addition to the scaffold's electrical conductivity and injectability, MG-63 cells' proliferation and attachment greatly improved, showing a promising application hope of tissue engineering in vivo. Evidence suggests that AuNPs stimulates primary osteoblast and mesenchymal stem cell differentiation by activating the extracellular signal-regulated kinase (ERK)/mitogen- 


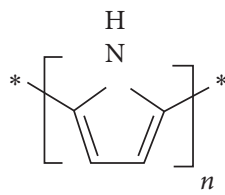

Polypyrrole (PPy)

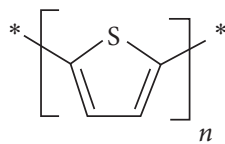

Polythiophene (PT)<smiles>CCC(C)(C)Nc1ccc(Nc2ccc(C)cc2)cc1</smiles>

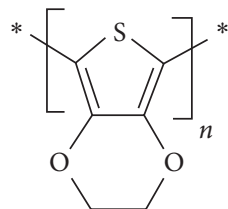

Polyethylene dioxythiophene (PEDOT)

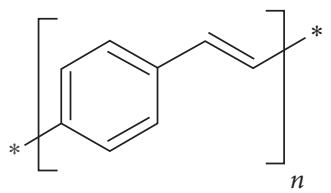

Polyphenylene vinylene (PPV)

Figure 1: Chemical structures of various conductive polymers [12].

TABle 1: Some application of conductive polymer hydrogels in biomedicine.

\begin{tabular}{|c|c|c|c|c|}
\hline $\begin{array}{l}\text { Hydrogel } \\
\text { matrix }\end{array}$ & $\begin{array}{c}\text { Conductive } \\
\text { polymer }\end{array}$ & Major outcomes & Cells & References \\
\hline GelMA & PPy & Self-healing, good blood, and cell compatibility & $\mathrm{C}_{2} \mathrm{C}_{12}$ cells & {$[22]$} \\
\hline $\begin{array}{l}\text { Dopamine- } \\
\text { gelatin }\end{array}$ & PPy & $\begin{array}{l}\text { Combination therapy improves myocardial function after } \\
\text { myocardial infarction }\end{array}$ & $\begin{array}{l}\text { L929 cells and } \mathrm{H}_{9} \mathrm{C}_{2} \\
\text { myocardial cells }\end{array}$ & {$[23]$} \\
\hline $\begin{array}{l}\text { Tannic acid } \\
\text { (TA) } \\
\end{array}$ & PPy & $\begin{array}{c}\text { Relatively high electrical conductivity can activate endogenous } \\
\text { neural stem cell differentiation in the lesion area }\end{array}$ & Neural stem cells & {$[24]$} \\
\hline PVA & PPy & $\begin{array}{c}\text { The electrochemical redox properties of conductive polymers } \\
\text { and their swelling capacity associated with PVA networks and } \\
\text { molecular diffusivity bind to stimulate response to drug } \\
\text { delivery }\end{array}$ & - & {$[25]$} \\
\hline Collagen & PPy & $\begin{array}{l}\text { The gel is based on collagen and PPy-b-PCL for the } \\
\text { bioprinting of neural tissue constructs }\end{array}$ & PC12 cells & {$[26]$} \\
\hline Chitosan & $\begin{array}{l}\text { Aniline } \\
\text { oligomers }\end{array}$ & $\begin{array}{c}\text { The glass transition temperature and thermal properties of } \\
\text { aniline oligomers were adjusted to reduce the swelling rate; } \\
\text { drug delivery of nerve tissue }\end{array}$ & PC12 cells & {$[27]$} \\
\hline Chitosan gel & $\begin{array}{l}\text { Aniline } \\
\text { oligomers }\end{array}$ & $\begin{array}{c}\text { Significantly promoted motor neuron-like cell differentiation } \\
\text { of human olfactory ectomesenchymal stem cell }\end{array}$ & $\begin{array}{c}\text { Human olfactory } \\
\text { ectomesenchymal stem cell }\end{array}$ & {$[28]$} \\
\hline Gel & PANi & $\begin{array}{c}\text { The BMSC hydrogel could significantly improve the behavior } \\
\text { of PD mice and the level of neurotrophic factors in the } \\
\text { substantia nigra }\end{array}$ & BMSCs & {$[29]$} \\
\hline PEG & $\begin{array}{l}\text { Aniline } \\
\text { oligomers }\end{array}$ & $\begin{array}{l}\text { The conductivity of hydrogel is close to natural heart tissue, } \\
\text { suitable for encapsulating } \mathrm{C}_{2} \mathrm{C}_{12} \text { myoblasts and } \mathrm{H}_{9} \mathrm{c}_{2} \text { heart } \\
\text { cells to repair the heart }\end{array}$ & $\begin{array}{l}\mathrm{C}_{2} \mathrm{C}_{12} \text { myoblasts and } \mathrm{H}_{9} \mathrm{c}_{2} \\
\text { heart cells }\end{array}$ & {$[30]$} \\
\hline GelMA & PEDOT : PSS & $\begin{array}{l}\text { Mechanically flexible and conductive hydrogels with } \\
\text { adjustable properties }\end{array}$ & $\mathrm{C}_{2} \mathrm{C}_{12}$ cells & {$[31]$} \\
\hline Cs/gel & PEDOT & $\begin{array}{l}\text { Improves electrical and mechanical properties while reducing } \\
\text { porosity, water absorption, and biodegradability }\end{array}$ & PC12 cells & {$[32]$} \\
\hline
\end{tabular}

activated protein kinase (MAPK) and p38 MAPK pathways, respectively [45, 46]. Also, Ag nanoparticles' (AgNPs) unique optical, electrical, and antibacterial properties make them widely used in EHs synthesis. Makvandi et al. [41] prepared Ag nanoparticles in a completely biocompatible and nontoxic solvent-free process using corn silk extract CSE in the water-based agent by a microwave-assisted method. They then coated the Ag nanoparticles in pluronic/ hyaluronic acid/ $\beta$-tricalcium phosphate/CSE hydrogels, creating hydrogels that gelled at temperatures close to those of humans and presenting ideal antibacterial activity while promoting high bone differentiation in MSC cells. Interestingly, AgNPs can also induce actin polymerization and increase cytoskeletal tension and activate RhoA to promote the osteogenic differentiation of urine-derived stem cells [47]. A recent study modified silk protein/nanohydroxyapatite hydrogels with in situ synthesized Ag and $\mathrm{Au}$ nanoparticles (AgNP and AuNP) using tyrosine amino acids 
TABLE 2: Some application of conductive metallic nanoparticle hydrogels in biomedicine.

\begin{tabular}{|c|c|c|c|c|}
\hline Hydrogel matrix & $\begin{array}{c}\text { Conductive metal } \\
\text { nanoparticles }\end{array}$ & Major outcomes & Cells & References \\
\hline Chitosan $/ \kappa$-carrageenan & Au nanoparticles & $\begin{array}{c}\text { Au nanoparticles act as a conductive component to } \\
\text { enhance cell growth and adhesion }\end{array}$ & MG-63 cells & [39] \\
\hline $\begin{array}{l}\text { poly(serinol hexamethylene } \\
\text { urea)-co-PNIPAM }\end{array}$ & Au nanoparticles & $\begin{array}{l}\text { Myocardial cells improved in long-term viability, } \\
\text { cardiac marker expression, and increased Cx } 43 \text { area }\end{array}$ & $\begin{array}{l}\text { Cardiac fibroblasts; } \\
\text { ventricular myocyte }\end{array}$ & [9] \\
\hline GelMA & Au nanoparticles & $\begin{array}{l}\text { Improved compressive strength and mechanical } \\
\text { modulus, degradation and swelling behavior, and } \\
\text { uniform cell proliferation arrangement }\end{array}$ & H9C2 heart cells & {$[40]$} \\
\hline Hyaluronic acid & Ag nanoparticles & $\begin{array}{l}\text { Nontoxic, antibacterial activity, and promoting } \\
\text { osteogenesis }\end{array}$ & L929 cells & {$[41]$} \\
\hline Agar, fumaric acid & Ag nanoparticles & $\begin{array}{c}\text { Antibacterial, promoting wound healing, and } \\
\text { angiogenesis }\end{array}$ & 3T3-L1 fibroblast & {$[42]$} \\
\hline $\begin{array}{l}\text { Fibroin/ } \\
\text { nanohydroxyapatite }\end{array}$ & $\begin{array}{c}\mathrm{Au} \text { and } \mathrm{Ag} \\
\text { nanoparticles }\end{array}$ & $\begin{array}{c}\text { Showing strong antibacterial activity and the } \\
\text { properties of antifixation and antiplankton, which } \\
\text { can reduce the adhesion and further accumulation } \\
\text { of bacteria }\end{array}$ & MG63 cells & {$[43]$} \\
\hline Chitosan/PEG & $\begin{array}{c}\mathrm{Fe}_{3} \mathrm{O}_{4} \\
\text { nanoparticles }\end{array}$ & $\begin{array}{l}\text { Magnetic hydrogels significantly increased the } \\
\text { temperature under magnetic field and effectively } \\
\text { improved the differentiation of MSC into bone }\end{array}$ & MSC & {$[44]$} \\
\hline
\end{tabular}

[43]. Nanocomposite hydrogels exhibited enhanced mechanical stiffness due to the presence of NP. These materials also allow osteoblasts to attach and spread.

2.3. Conductive Graphene and CNTs Hydrogels. Graphene as biological matrix graphene, its derivatives of conductive materials, and carbon nanotubes (CNTs) have led to nanomaterial research upsurge over the past few decades. The high mechanical strength, effective surface area, and high electrical conductivity have made mixed hydrogels based on carbon-based materials attract much attention. The excellent characteristics of carbon-based materials (such as high cellular absorption, high stability, and electromagnetic behavior) make them one of the most promising nanofillers for various applications $[48,49]$. However, some factors hinder the random distribution of nanomaterials in polymer networks. The wet-spinning method is one of the solutions of scientists' efforts overcoming these barriers. Wet-spinning, as an efficient and straightforward assembly technique, can convert carbon-based nanomaterials into fibers with a highly ordered structure, and of all the carbon-based nanomaterials, the liquid crystal behavior makes graphene optimum for making wet spun fibers.

Sepehr Talebian et al. [50] employed graphene nanocrystals and highly biocompatible alginates to build composite fibers by mature wet-spinning technique. The composite fiber incorporates adequate flexibility, high-level $\mathrm{C}_{2} \mathrm{C}_{12}$ myoblast compatibility, and mechanical strength, which becomes a promising alternative in tissue engineering. Analogously, CNT presents a low solubility in a water-based environment, resulting in poor dispersion. Due to the attractive interaction of Van der Waals' force between the tubules, this structural pattern of agglomeration occurs, making CNT insoluble in most organic solvents [51]. Surface coating or functionalization of other functional groups serves as the primary solution at present. In a recent study, Liang et al. [52] designed and successfully synthesized gelatin-grafted-dopamine (GT-DA) and polydopaminecoated carbon nanotubes (CNT-PDA). Antibacterial, adhesive, antioxidant, and conductive Gt-DA/chitosan/CNT hydrogels designed by oxidative coupling of the catecolic groups can serve as the multifunctional bioactive dressings for infected wound healing. Another study functionalizes the CNT by using the formononetin $(\mathrm{Ft})$, a bioactive isoflavone found in the hydroalcoholic extract of red propolis, to prepare nanocomposite [53]. Incorporating the nanocomposite in a gelatin methylacryloyl prepolymer formula formed the biocompatible hydrogel under ultraviolet light, which can be a carrier of anti-inflammatory molecules to treat spinal cord injury by in situ injection. There are more applications of conductive graphene and CNTs hydrogels in biomedicine, seen in Table 3.

\section{EHs Synthesis}

The cross-linking mechanism classifies EHs synthesis into physical-cross-linking, covalent-cross-linking, and supramolecular-cross-linking [56]. Physical-cross-linking mixes conductive and nonelectrically active materials into glue by physical action. However, the mechanism has the limitation of the uncontrollability of the reaction process and conditions. Covalent-cross-linking refers to covalent bonds' reaction between components, which can enhance the chemical activity by incorporating different functional groups. The covalent reaction can elevate hydrogels' mechanical properties and stability. At the same time, the special covalent reaction monomer also limits the application scope of this method. Nevertheless, special covalent reactive monomers also narrow the covalent-cross-linking application scope. Supramolecular interactions include hydrophobic interactions, electrostatic interactions, host- 
TABLE 3: Some applications of conductive graphene and CNTs hydrogels in biomedicine.

\begin{tabular}{|c|c|c|c|c|}
\hline Hydrogel matrix & $\begin{array}{c}\text { Conductive carbon-based } \\
\text { nanomaterials }\end{array}$ & Major outcomes & Cells & References \\
\hline Alginate & Graphene & $\begin{array}{c}\text { Flexibility, mechanical strength, excellent electrochemical } \\
\text { level, and biocompatibility }\end{array}$ & $\begin{array}{c}\mathrm{C}_{2} \mathrm{C}_{12} \\
\text { fibroblasts }\end{array}$ & {$[50]$} \\
\hline Gelatin & CNT & $\begin{array}{c}\text { Antibacterial, adhesive, antioxidant, and electrical } \\
\text { conductivity }\end{array}$ & $\begin{array}{l}\text { L929 } \\
\text { fibroblasts }\end{array}$ & {$[52]$} \\
\hline GelMA & CNT & $\begin{array}{c}\text { Stable hydrogel was formed in situ to treat spinal cord injury; } \\
\text { anti-inflammatory substance carrier }\end{array}$ & $\begin{array}{l}\text { L929 } \\
\text { fibroblasts }\end{array}$ & {$[53]$} \\
\hline GelMA & Graphene oxide & $\begin{array}{l}\text { Electrical conductivity, flexibility, mechanical stability, and } \\
\text { permeability, improving peripheral nerve regeneration }\end{array}$ & PC12 cells & {$[18]$} \\
\hline $\begin{array}{l}\text { N-Carboxyethyl } \\
\text { chitosan }\end{array}$ & CNT & $\begin{array}{c}\text { In vivo photothermal antibacterial, good hemostasis, and } \\
\text { biodegradability }\end{array}$ & $\begin{array}{l}\text { L929 } \\
\text { fibroblasts }\end{array}$ & {$[54]$} \\
\hline Agarose & CNT & $\begin{array}{l}\text { Promoting the proliferation and differentiation of bone } \\
\text { mesenchymal stem cell lines }\end{array}$ & BMSCs & {$[55]$} \\
\hline
\end{tabular}

guest complexation, $\pi-\pi$ superposition, hydrogen bonds, and a combination of their various reactions. The supramolecular cross-linking mechanism has seen an extensive application and increasing popularity in EHs synthesis of carbon-based materials. The conductive material category can divide the specific technique into in situ generations, doping blending, grafting, self-assembly, coating, and others, with referents in the following review.

Doping befitting cross-linkers, the conductive materials' dispersion uniformity, and the coating adhesion fastness are the critical problems in the synthesis. Synthetic interpenetrating polymer network (IPN) conductive hydrogels by mutual and continuous osmosis of conductive polymer chains and hydrogel matrix chains at the molecular level could achieve the uniform electrical and mechanical properties of conductive hydrogels, suggesting a method for polymerizing conductive polymers in situ in hydrogel matrix [57]. Natural polymers such as chitosan, gelatin, cellulose, and hyaluronic acid have seen application to preparing conductive hydrogels to remove the limitation of the uniform distribution of hydrophobic conductive polymers in conventional hydrogel matrix [58-62]. The good affinity of natural polymers' molecular structure for conductive polymers is conducive to integrating conductive polymers and hydrogel networks. Besides, a report came of a strategy that is reducing the distribution of ionic form of metal nanoparticles in hydrogel matrix could advantage the uniform dispersion of conductive metal nanoparticles in hydrogel matrix [63]. The uniform distribution of carbonbased conductive materials can refer to the wet-spinning technique mentioned above and the colloidal chemistrybased method. A strong recommendation is to read the following reviews for a deeper acquisition of the synthesis and classification of conductive hydrogels $[12,14,56,64]$.

\section{Electroconductive Hydrogels for Biomedical Applications in Orthopedics}

Repairing irreversible damage of naturally healthy bone caused by trauma, cancer, surgery, congenital malformations, and others has been a world-class problem [65]. The origin and economic problems of autograft and allograft have turned the focus of bone and surrounding tissue repair into engineering materials. To date, several attempts have been made to adapt conventional biomaterials to bone regeneration and integration into surrounding tissues [66]. Acknowledgedly, biomaterials' ultimate goal shall be to replace or restore tissue function, rebuild the body's damaged parts, assist in healing and beautifying, and others [67]. Biomaterials involve not only the bone tissue but also the reconstruction and repair of cartilage, ligaments, muscles, blood vessels, and others. Hence, further improvement is necessary for the ability of various materials to selectively guide and influence the function of cells and tissues which need implantation at specific sites. Evidence of increasing angiogenesis and bone conductivity in bone repair models suggests hydrogels as one promising alternative for forming such composites [68]. Many polymers that form hydrogels are the main components of the extracellular matrix of bone or other tissues, such as hyaluronic acid and collagen. Except for cell culture and tissue engineering scaffolds, hydrogels present the merits to control drug and soluble factor release, injectability, and self-healing, elevating them with an inviting bioengineering tool for bone defects in different locations, sizes, and shapes. Besides the eminent suitability for bone's piezoelectric property, EHs also have the electrical activity in biological performance, facilitating the transformation and communication of bioelectrical signals between cells. It is convincing that EHs can better accomplish the goal of orthopedic biology application.

4.1. Cell Culture Matrix. How cell culture matrix can simulate the microenvironment of cells in vivo to the maximum has been the most critical issue with ongoing energetic research. Excellent biocompatibility, stable 3D structure, enough water for cell movement, and the ability to maintain communication between cells are all essential. The porous microstructure of EHs, ion type and concentration, mechanical modulus, electrical properties, specific molecules, and external stimuli will affect cell growth, proliferation, adhesion, and differentiation [69].

Hydrogel film is a common matrix morphology in cell culture. Jiang et al. [70] designed a photo-induced biocompatible self-rolling conductive hydrogel film by combining dopamine cross-linking agents, multiwalled carbon 
nanotube (MWCNT), and poly(ethylene glycol) diacrylate (PEGDA). Michael addition reaction of dopamine and N'N'methylene diacrylamide synthesizes cross-linking agent, the approach of which introduces the double bond to dopamine and further cross-links dopamine to the main chain of the structure, namely, PEGDA. When culturing BMSC cells in the hydrogels as mentioned above, the real-time PCR method demonstrated expression increases of osteoblasts such as bone sialoprotein (BSP), alkaline phosphatase (ALP), and osteopontin (OPN) with the increase of MWCNT concentration, which was also confirmed by cytoskeleton staining, seen in Figure 2. Besides EHs morphology, their mechanical strength and the addition of specific molecules also affect its ability to grow cells. Wang et al. [71] used L-cysteine to reduce graphene oxide (GO), in which L-cysteine ACTS worked as a cross-linking agent while reducing the overall toxicity of the material and bridging the GO nanosheets to form porous hydrogels. The resulting composite hydrogels also presented an electrical conductivity increase of four to five orders of magnitude compared to GO alone. The good adhesion and growth of osteoblasts on this hydrogel indicated that this hydrogel has the potential to be the matrix for cell culture and electrical stimulation to change cell behavior. Currently, external electrical stimulation has assisted EHs in making achievement in cell culture. A recent study tried to introduce magnetoelectric composite spheres of $\mathrm{CoFe}_{2} \mathrm{O}_{4} / \mathrm{PVDF}$ into methacrylated gellan gum (GGMA) to prepare injectable EHs, with Young's modulus of $20 \mathrm{kPa}$, and the activity of MC3T3-E1 preosteoblasts better than 80\% [72]. The external magnetic field could trigger a dynamic electrical response to improve cell regeneration. The external electrical stimulation could also induce the osteogenic differentiation of stem cells $[73,74]$. Evidence shows that small scaffolds for graphene cellulose could facilitate the osteogenic differentiation of adipose-derived stem cell (ADSC), which is applicable for cell culture and engineering approach [75].

Extensive muscle damage and complex joint lesions frequently occur in orthopedic diseases, requiring a cell culture matrix that guides muscle cells and chondrocytes' behavior. Recently, scientists have developed microfluidically self-assembled graphene-polysaccharide nanocomposite fiber hydrogel films. The addition of graphene to the fibrous hydrogel film could improve its wettability, electrical conductivity, tensile strength, and toughness. The arranged fibrous film structure and enhanced electrical conductivity would lead to myoblasts' differentiation to form multinucleated myotubes [76]. Srisuk et al. proposed PANi-GG electroactive spongy-like hydrogels as potential materials to modulate myoblast biological response. The results demonstrated that $\mathrm{C}_{2} \mathrm{C}_{12}$ myoblasts adhered to PANi-GG electroactive spongy-like hydrogels, showing a strong ability to proliferate and differentiate into muscle tubes, seen in Figure 3 [77]. In terms of cartilage formation, recent studies have found that GO flakes absorb transforming growth factor $\beta 3$ (TGF- $\beta 3$ ) and then blended them into collagen hydrogels. Encapsulating human mesenchymal stem cells (hMSCs) in the same hydrogel found higher chondrogenic gene expression and chondrogenic extracellular matrix deposition, and the effect lasted for one month [78].

4.2. Scaffold for Tissue Engineering. Tissue engineering technology is expected to treat human tissue loss successfully, and full-featured scaffold material is the foundation of successful tissue engineering [54]. Excellent biocompatibility, intercellular information exchange involving electrical signals, and porous network structure make EHs appropriate support for cell formation of tissues and organs, as well as a template to guide the growth and construction of new tissues [79].

Hydrogel/fiber composites are a promising approach to overcome the inherent limitations of the original hydrogel or fiber scaffold [80]. Fiber coated by hydrogel matrix can improve the inherent cellular migration of fibers and the low mechanical properties of hydrogels [81], seen in the analogous attempt of EHs preparation. The introduction of the precursor solution, consisting of alginate oxide, hyaluronic acid oxide, gelatin, and graphene, into the electrospinning $\mathrm{PCL} / \mathrm{PANi}$ fibers could prepare hydrogel/fiber composite material which exhibited enhanced elastic modulus, roughness, and electrical conductivity and also better supported human osteoblasts' adhesion, proliferation, and morphology [82]. In skeletal muscle tissue engineering, EHs composed of coaxial electrospinning polymerization ( $\varepsilon$-caprolactone), multiwalled carbon nanotubes, polyvinyl alcohol, and polyacrylic acid (PCL-MWCNT-H) can increase the formation of myoblast myoblasts by electrical stimulation [83]. However, the mechanical strength is slightly higher than that of muscle, which needs further optimization. Guo et al. demonstrated that self-healable conductive injectable hydrogels based on dextran-graftaniline tetramer-graft-4-formylbenzoic acid and N-carboxyethyl chitosan could be synthesized at physiological conditions [84]. Hydrogels represent sufficient in vivo injection capacity and biodegradability, and it can encapsulate various types of cells with sufficient vitality into hydrogels. The release of $\mathrm{C}_{2} \mathrm{C}_{12}$ cells from hydrogels exhibits that the released cells still could proliferate continuously. These selfrepair conductive hydrogels promote the regeneration of skeletal muscle in the volume muscle loss injury model.

The uniform distribution of conductive materials in EHs has always been a broad concern, which appears in the simple blending process [85]. A recent study illustrated that independent graphene/hydroxyapatite hydrogels by collochemistry unprecedented homogeneity in their 3D structure [86]. Hydrogels exhibit excellent mechanical properties, high electrical conductivity, high specific surface area, and good cellular compatibility, making them an excellent candidate for bone tissue engineering applications.

Injectable conductive hydrogels have attracted significant attention from orthopedic tissue engineering and regenerative medicine [87] because injectable conductive hydrogels can repair tissue defects of any shape and avoid invasive surgery. Zhao et al. [88] found that introducing polyaniline into QCS copolymers could significantly reduce the cytotoxicity of QCS and enhance the antibacterial activity of QCS through 


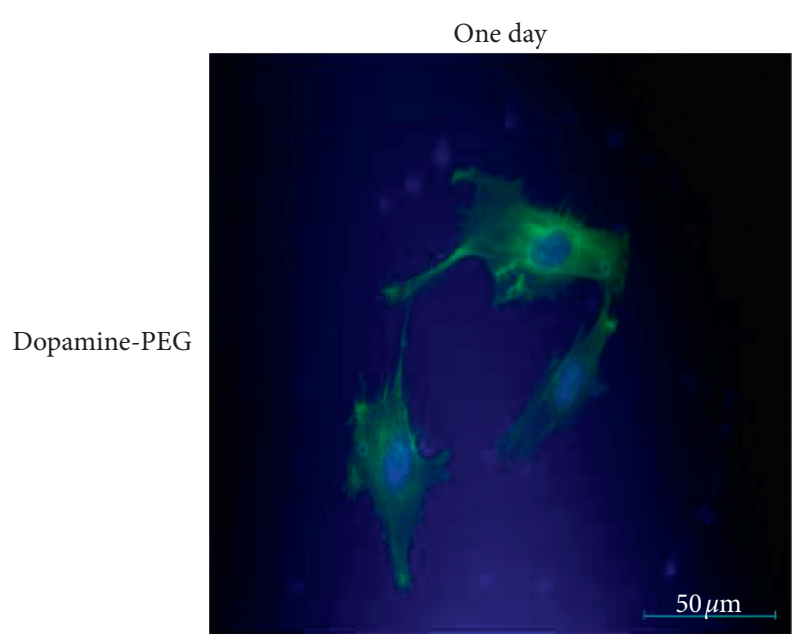

(a)

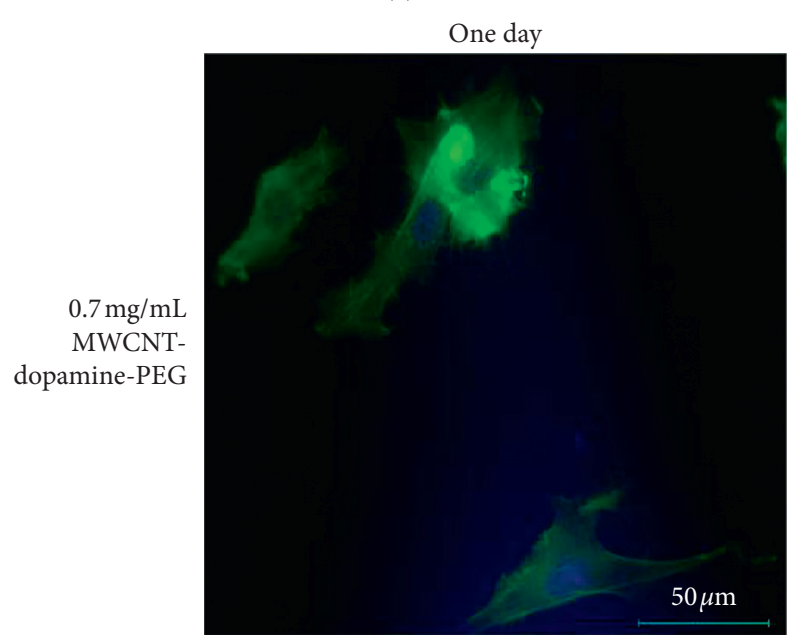

(c)

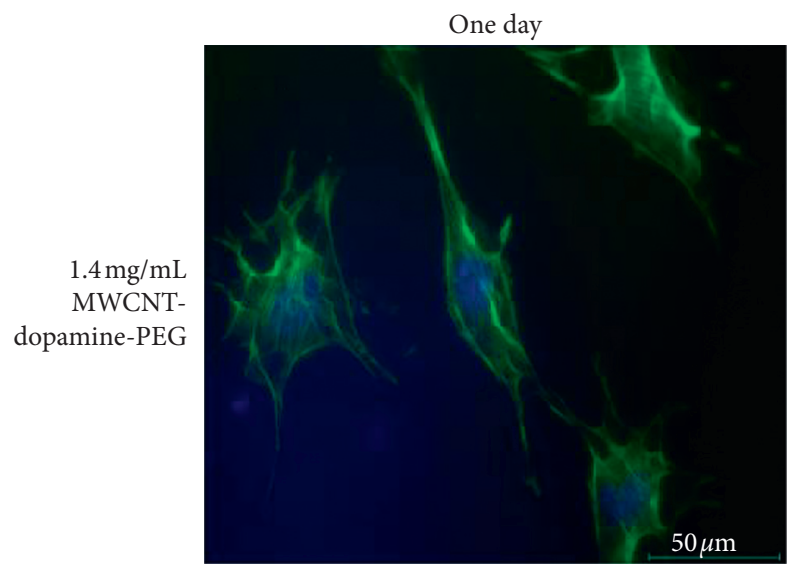

(e)

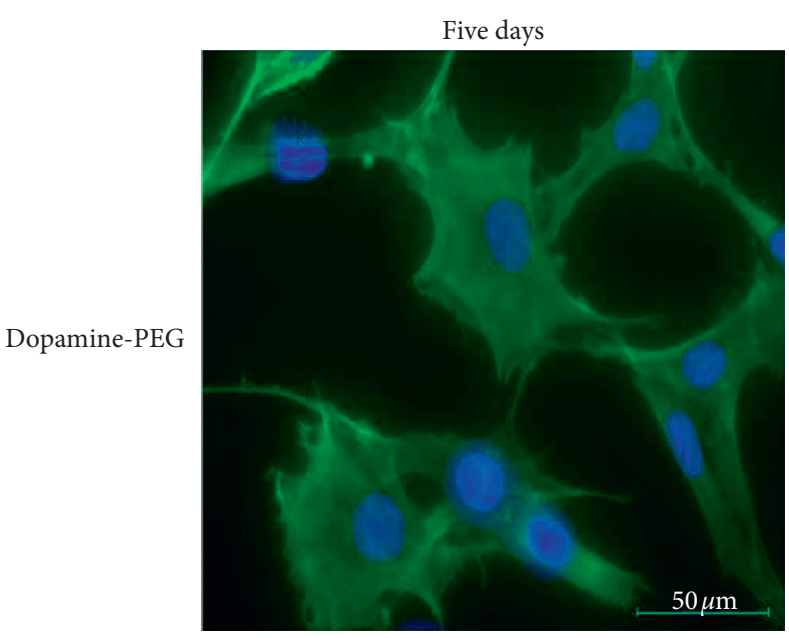

(b)

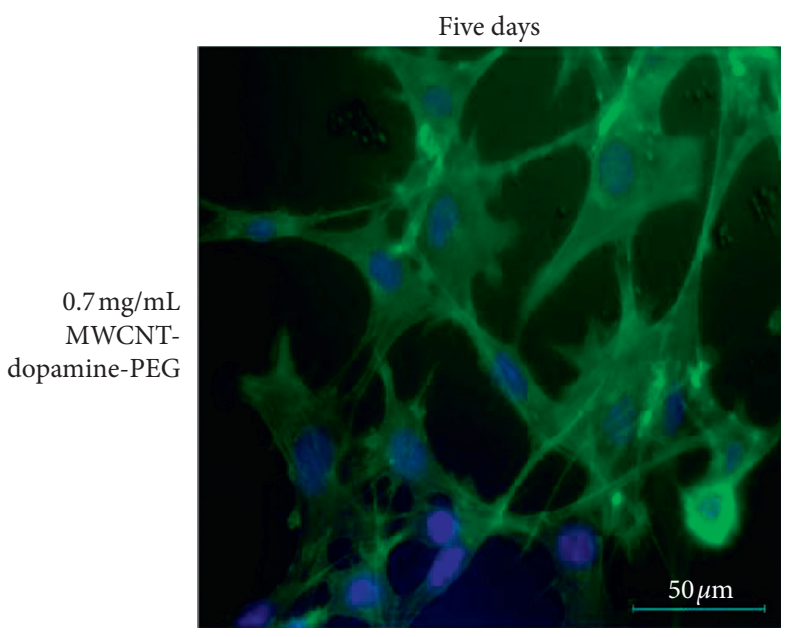

(d)

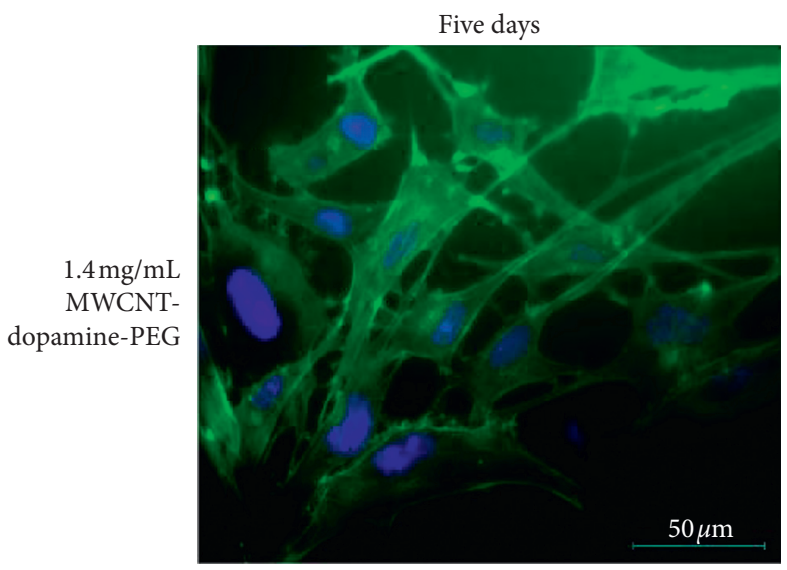

(f)

FIGURE 2: BMSCs were cultured on hydrogels with different concentrations of MWCNT to examine the effect of MWCNT concentration on cell morphology. Green represents the cytoskeleton and blue represents the nucleus [70].

synergistic action. The antibacterial tests of Escherichia coli and Staphylococcus aureus in vitro verified the excellent antibacterial activity of antimicrobial conductive biodegradable hydrogels prepared by the method mentioned above. Moreover, subsequent in vitro experiments showed that this hydrogel had no cytotoxicity to ADMSC and promoted $\mathrm{C}_{2} \mathrm{C}_{12}$ myoblasts' proliferation, which can serve as a new bioactive scaffold for skeletal muscle tissue engineering.

EHs coating on metal implants is also a form of tissue engineering. Tan et al. [89] bonded the methacrylate gelatin/ 


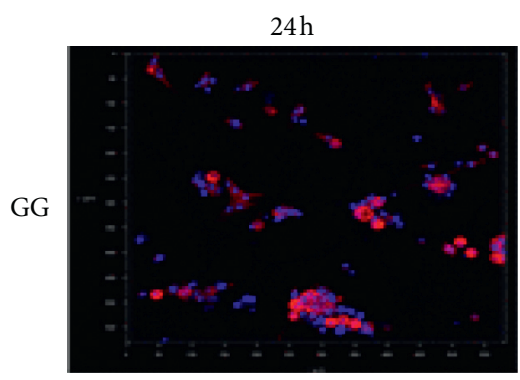

A

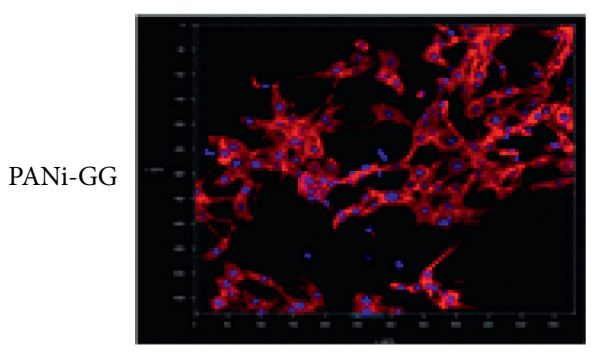

$\mathrm{D}$

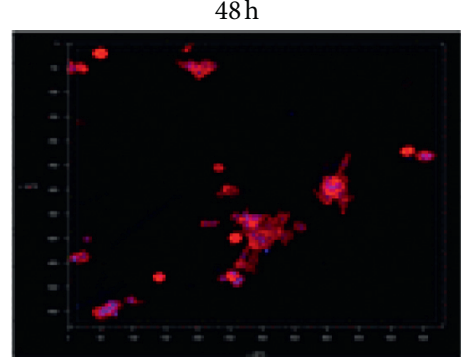

B

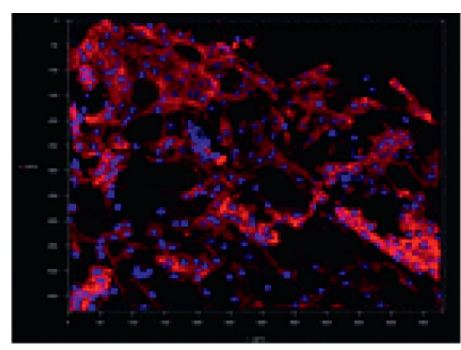

E

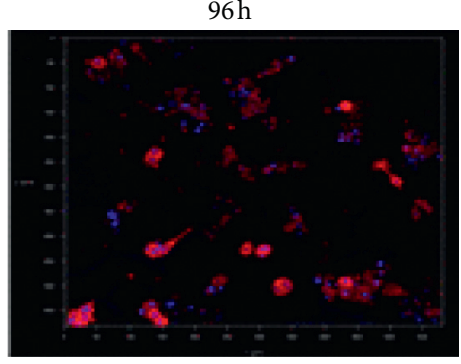

C

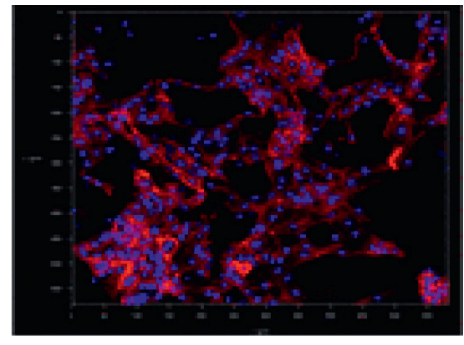

F

(a)

GG
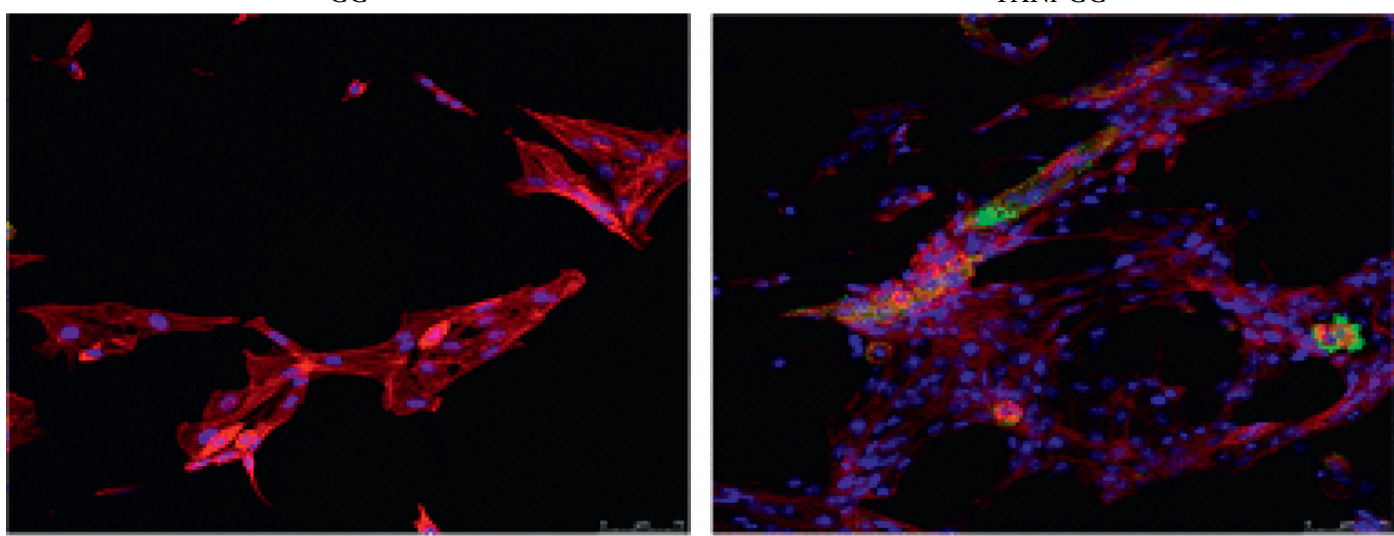

B

(b)

Figure 3: (a) $\mathrm{C}_{2} \mathrm{C}_{12}$ cells morphology cultured on GG (A), (B), and (C) and PANi-GG spongy-like hydrogels (D), (E), and (F). (b) $\mathrm{C}_{2} \mathrm{C}_{12}$ immunostaining with antimyosin after 7 days of culture on GG (A) and PANi-GG spongy-like hydrogels (B) [77]. Copyright (C) 2018, American Chemical Society.

polypyrrole conductive hydrogels coating to the titanium surface through a UV-initiated radical thiol-ene click reaction. The hydrogel coating on the surface presented the desired properties of high electrochemical activity and high mechanical stability. Bone mesenchymal stem cells cultured on hydrogel matrix showed high cell viability. However, the fastness of similar coatings requires further verification. Tendon and cartilage bind to bone at a very strong interface, but such a highly ductile interface has not yet found achievement between the porous surfaces of synthetic hydrogels and engineered solids. One current design strategy is to covalently anchor long-chain polymer networks of tough EHs to nonporous concrete surfaces, which can achieve by silanizing these surfaces [90]. They designed the synthetic hydrogels, which contain $90 \%$ water, to tough, transparent, and electrical bindings, conductive to adhere to the porous surfaces of various solids, with an interfacial toughness that was superior to that of tendon-bone and cartilage-bone interfaces. The electrical conductivity provides the basis for the reliability between the hydrogel ion conductor and the metal electrode in the future, making many future research directions and applications possible, such as biosensors and robot structure.

4.3. Drug/Growth Factor Delivery. Response to electrical stimulation is a significant advantage of EHs over conventional biomedical hydrogels. The mixing of conductive 


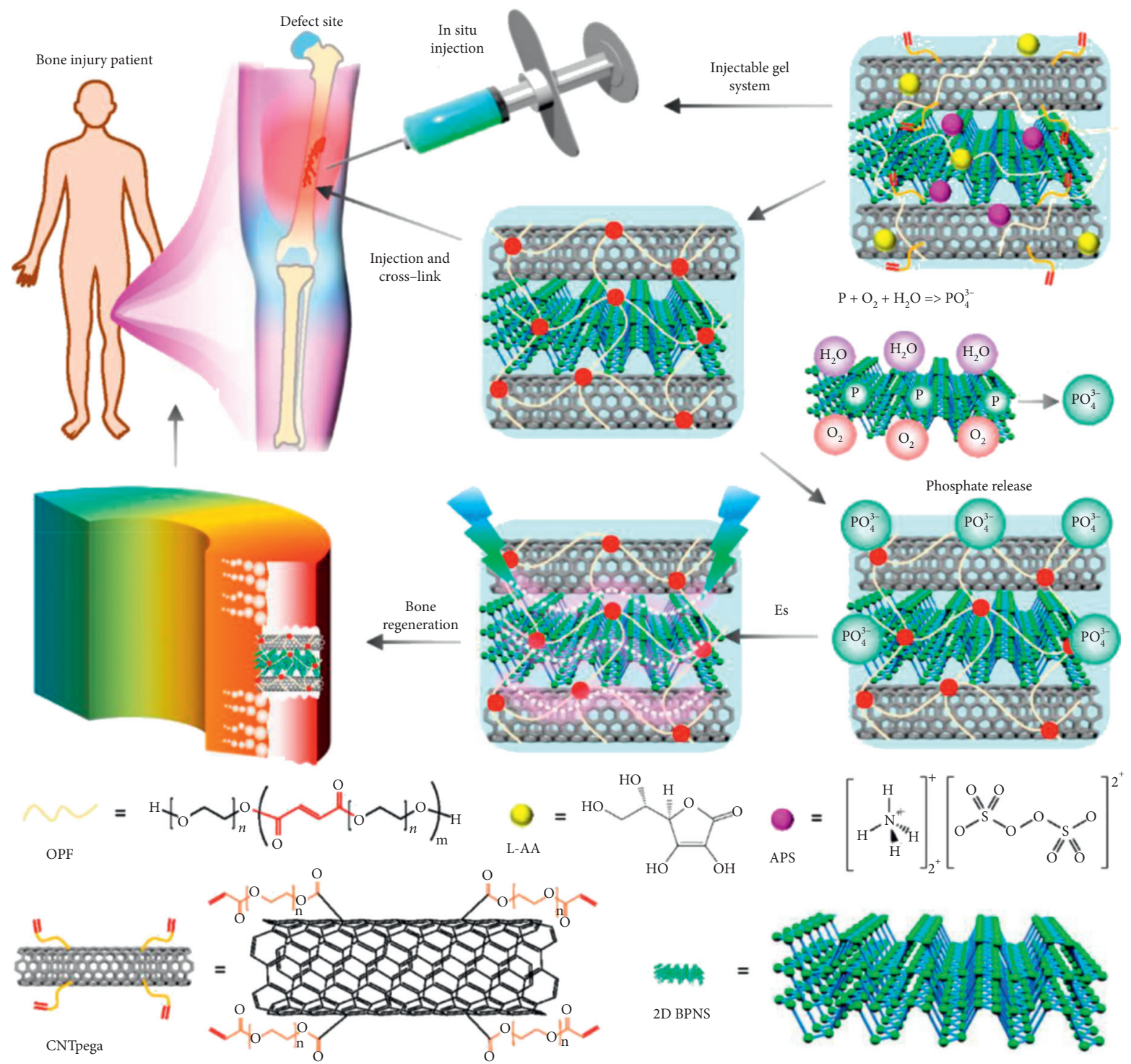

Figure 4: Schematic demonstration of the novel injectable gel with continuous phosphate ion release and electrical responsiveness to promote cell osteogenesis and bone regeneration [4]. Copyright (c) 2020 American Chemical Society.

materials and hydrogels provides the potential to extend drug delivery scope and quantity, thus creating new opportunities for more excellent use value [91]. The combination of EHs and electroresponsive drug delivery is an attractive method for locally adjustable drug release to meet therapeutic requirements [92]. Controlled by external electrical stimulation, EHs produced an "on-off" precise drug delivery system [93]. Orthopedic EHs are also working on this. Jin et al. [94] designed a biocompatible, biodegradable conductive hydrogel system with electric response characteristics by blending dextran and electroactive aniline tripolymers with hexamethylene diisocyanate as crosslinking agents to prepare a hydrogel network, which is a new type of intelligent drug delivery system. Fibroblast culture and subcutaneous implantation demonstrated good biocompatibility. Moreover, when applying an external voltage, hydrogels could rapidly release more dexamethasone, preliminarily realizing the precise concept of "on- off” drug release. Similarly, Qu et al. [95] successfully synthesized antibacterial conductive hydrogels based on $\mathrm{CP}$ copolymer and OD polymer and demonstrated their application as drug carriers with a dual response to electric field and $\mathrm{pH}$ to achieving on-off local slow release. Qian et al. [96] developed a novel electrophysiological CNT gel scaffold based on the Wats-Crick base-pairing mechanism through the intermolecular hydrogen bond between thymine and adenine, which targets explicitly BMP-2 delivery and ASC's osteogenic effect. In combination with electrical stimulation, ASC's inoculation into CNT gel scaffolds demonstrated a strong spontaneous and stimulating synchronous osteogenesis.

Currently, EHs applied to release drugs or growth factors without external electrical stimulation exist in many cases of orthopedic biomedical application. Aparna et al. [97] synthesized a new injectable, conductive, and thermosensitive gel composed of chitosan/chitosan-grafted polyaniline (Chi- 
G-PANi). In vitro cell culture with MC3T3-E1and $\mathrm{C}_{2} \mathrm{C}_{12}$ cells demonstrated that these gels were suitable for cell adhesion and proliferation. Culturing MC3T3-E1cells with the gel would enhance the significant osteogenic markers (such as ALP and calcium generation). Synchronously, the MC3T3-E1 could continue to release vancomycin for 28 days, a promising material for osteomyelitis and bone regeneration. Also, scientists have recently synthesized new injectable CNT and black phosphorus (BP) gels, seen in Figure 4 [4]. The gels employed biodegradable oligo(poly(ethylene glycol) fumarate) (OPF) polymer as the crosslinked substrate, with the addition of a cross-linked CNTpoly(ethylene glycol)-acrylate (CNTpega) to provide mechanical support and electrical conductivity. The infusion of two-dimensional (2D) black phosphorus nanosheets was to assist tissue regeneration through the steady release of phosphate. Experiments showed that this newly developed BP-CNTpega-gel can enhance the adhesion, proliferation, and osteogenic differentiation of MC3T3 preosteoblasts. By electrical stimulation, the expression of several critical osteogenic pathway genes further enhanced osteogenesis. BPCNTpega-gel showed excellent in situ gelation and crosslinking, filling the femur defect, the vertebral cavity, and the posterior lateral spine fusion site in rabbits. Besides, polylactic acid particles loaded with $\mathrm{H}_{2} \mathrm{O}_{2}$ were prepared in some research to solve the problem of insufficient oxygen content before vascularization in the defect. Then, gelatin-grafted polypyrrole with different pyrrole contents and pectin oxidized by periodate were synthesized to obtain injectable conductive hydrogel/particulate scaffolds in which catalase was implanted and captured. The scaffold gains the advantages of electrical conductivity, injectability, compatibility, and continuous oxygen release [98].

Unfortunately, no experimental evidence of drug or growth factor release in vivo supports the application of the above delivery system, which also needs further exploration of the therapeutic dose range and sustained long-term release. More importantly, in conjunction with external electrical stimulation to construct intelligent systems for electrically responsive drug delivery, are future orthopedic applications.

\section{Conclusion}

From the perspective of biological applied materials design objectives, $\mathrm{EH}$ can be an ideal platform for cell culture, tissue engineering scaffolds, drug/growth factor delivery, and others. In EHs, the combination of conventional biomedical hydrogels and conductive materials can produce a system with a $3 \mathrm{D}$ porous structure, high water content, biocompatibility, stable mechanical properties, excellent electrochemical performance, multistimulus response, and other advantages. However, some disadvantages remain, such as uneven dispersion of conductive materials, biotoxicity of some conductive materials, low degradation, unstable electrochemical properties in the biological environment, proton conductivity, and electron conductivity identification. Currently, determining the parameters that match the best conductivity and electrical stimulation for different applications requires more in vivo and clinical data. The intersection of electricity and medicine is an approach to treat orthopedic diseases in the future. It is convincible that the materials and biomedicine domain's joint efforts can achieve a breakthrough in the development and research of EHs.

\section{Conflicts of Interest}

The authors report no conflicts of interest in this work.

\section{References}

[1] H. D. N. Tran, K. D. Park, Y. C. Ching, C. Huynh, and D. H. Nguyen, "A comprehensive review on polymeric hydrogel and its composite: matrices of choice for bone and cartilage tissue engineering," Journal of Industrial and Engineering Chemistry, vol. 89, pp. 58-82, 2020.

[2] P. Abdollahiyan, F. Oroojalian, A. Mokhtarzadeh, and M. Guardia, "Hydrogel-based 3D bioprinting for bone and cartilage tissue engineering," Biotechnology Journal, vol. 15, no. 12, Article ID 2000095, 2020.

[3] N. Annabi, A. Tamayol, J. A. Uquillas et al., "25th anniversary article: rational design and applications of hydrogels in regenerative medicine," Advanced Materials, vol. 26, no. 1, pp. 85-124, 2014.

[4] X. Liu, M. N. George, L. Li et al., "Injectable electrical conductive and phosphate releasing gel with two-dimensional black phosphorus and carbon nanotubes for bone tissue engineering," ACS Biomaterials Science \& Engineering, vol. 6, no. 8, pp. 4653-4665, 2020.

[5] M. Toledano, M. Toledano-Osorio, Á. Carrasco-Carmona et al., "State of the art on biomaterials for soft tissue augmentation in the oral cavity. part II: synthetic polymers-based biomaterials," Polymers, vol. 12, no. 8, p. 1845, 2020.

[6] A. Zhang, Y. Liu, D. Qin, M. Sun, T. Wang, and X. Chen, "Research status of self-healing hydrogel for wound management: a review," International Journal of Biological Macromolecules, vol. 164, pp. 2108-2123, 2020.

[7] F.-C. Kao, P.-Y. Chiu, T.-T. Tsai, and Z.-H. Lin, "The application of nanogenerators and piezoelectricity in osteogenesis," Science and Technology of Advanced Materials, vol. 20, no. 1, pp. 1103-1117, 2019.

[8] S. Zhu, W. Jing, X. Hu et al., "Time-dependent effect of electrical stimulation on osteogenic differentiation of bone mesenchymal stromal cells cultured on conductive nanofibers," Journal of Biomedical Materials Research Part A, vol. 105, no. 12, pp. 3369-3383, 2017.

[9] B. Peña, M. Maldonado, A. J. Bonham et al., "Gold nanoparticle-functionalized reverse thermal gel for tissue engineering applications," ACS Applied Materials \& Interfaces, vol. 11, no. 20, pp. 18671-18680, 2019.

[10] A. Guiseppi-Elie, A. M. Wilson, and K. E. Brown, "Electroconductive hydrogels: novel materials for the controlled electrorelease of bioactive peptides," American Chemical Society, Polymer Preprints, Division of Polymer Chemistry, vol. 38, pp. 608-609, 1997.

[11] K. Gilmore, A. J. Hodgson, B. Luan, C. J. Small, and G. G. Wallace, "Preparation of hydrogel/conducting polymer composites," Polymer Gels and Networks, vol. 2, no. 2, pp. 135-143, 1994. 
[12] J. Min, M. Patel, and W.-G. Koh, "Incorporation of conductive materials into hydrogels for tissue engineering applications," Polymers, vol. 10, no. 10, p. 1078, 2018.

[13] K. Liu, S. Wei, L. Song, H. Liu, and T. Wang, "Conductive hydrogels-a novel material: recent advances and future perspectives," Journal of Agricultural and Food Chemistry, vol. 68, no. 28, pp. 7269-7280, 2020.

[14] A. Guiseppi-Elie, "Electroconductive hydrogels: synthesis, characterization and biomedical applications," Biomaterials, vol. 31, no. 10, pp. 2701-2716, 2010.

[15] Z. Shi, X. Gao, M. W. Ullah, S. Li, Q. Wang, and G. Yang, "Electroconductive natural polymer-based hydrogels," Biomaterials, vol. 111, pp. 40-54, 2016.

[16] L. Jian, Y. Wang, and Z. Liu, "Three-dimensional printing and injectable conductive hydrogels for tissue engineering application," Tissue Engineering Part B: Reviews, vol. 25, pp. 398-411, 2019.

[17] J. Stejskal, "Conducting polymer hydrogels," Chemical Papers, vol. 71, no. 2, pp. 269-291, 2017.

[18] J. Park, J. Jeon, B. Kim et al., "Electrically conductive hydrogel nerve guidance conduits for peripheral nerve regeneration," Advanced Functional Materials, vol. 30, no. 39, Article ID 2003759, 2020.

[19] J. Zhang, C. Wu, Y. Xu et al., "Highly stretchable and conductive self-healing hydrogels for temperature and strain sensing and chronic wound treatment," ACS Applied Materials \& Interfaces, vol. 12, no. 37, pp. 40990-40999, 2020.

[20] C. Qian, T. Higashigaki, T.-A. Asoh, and H. Uyama, "Anisotropic conductive hydrogels with high water content," ACS Applied Materials \& Interfaces, vol. 12, no. 24, pp. 2751827525, 2020.

[21] T. Nezakati, A. Seifalian, A. Tan, and A. M. Seifalian, "Conductive polymers: opportunities and challenges in biomedical applications," Chemical Reviews, vol. 118, no. 14, pp. 6766-6843, 2018.

[22] S. Wang, J. Lei, X. Yi et al., "Fabrication of polypyrrole-grafted gelatin-based hydrogel with conductive, self-healing, and injectable properties," ACS Applied Polymer Materials, vol. 2, no. 7, pp. 3016-3023, 2020.

[23] T. Wu, "Coadministration of an adhesive conductive hydrogel patch and an injectable hydrogel to treat myocardial infarction," ACS Applied Materials \& Interfaces, vol. 12, pp. 20392048, 2020.

[24] L. Zhou, L. Fan, X. Yi et al., "Soft conducting polymer hydrogels cross-linked and doped by tannic acid for spinal cord injury repair," ACS Nano, vol. 12, no. 11, pp. 10957-10967, 2018.

[25] A. M. Orduño Rodríguez, C. J. Pérez Martínez, T. del Castillo Castro, M. M. Castillo Ortega, D. E. Rodríguez Félix, and J. Romero García, "Nanocomposite hydrogel of poly(vinyl alcohol) and biocatalytically synthesized polypyrrole as potential system for controlled release of metoprolol," Polymer Bulletin, vol. 77, no. 3, pp. 1217-1232, 2020.

[26] S. Vijayavenkataraman, N. Vialli, J. Y.H. Fuh, and W. Feng Lu, "Conductive collagen/PPy-b-PCL hydrogel for bioprinting of neural tissue constructs," International Journal of Bioprinting, vol. 5, no. 2.1, pp. 31-43, 2019.

[27] B. Bagheri, P. Zarrintaj, S. S. Surwase et al., "Self-gelling electroactive hydrogels based on chitosan-aniline oligomers/ agarose for neural tissue engineering with on-demand drug release," Colloids and Surfaces B: Biointerfaces, vol. 184, Article ID 110549, 2019.

[28] Z. Bagher, Z. Atoufi, R. Alizadeh et al., "Conductive hydrogel based on chitosan-aniline pentamer/gelatin/agarose significantly promoted motor neuron-like cells differentiation of human olfactory ecto-mesenchymal stem cells," Materials Science and Engineering: C, vol. 101, pp. 243-253, 2019.

[29] J. Xue, Y. Liu, M. A. Darabi et al., "An injectable conductive gelatin-PANI hydrogel system serves as a promising carrier to deliver BMSCs for Parkinson's disease treatment," Materials Science and Engineering: C, vol. 100, pp. 584-597, 2019.

[30] R. Dong, X. Zhao, B. Guo, and P. X. Ma, "Self-healing conductive injectable hydrogels with antibacterial activity as cell delivery carrier for cardiac cell therapy," ACS Applied Materials \& Interfaces, vol. 8, no. 27, pp. 17138-17150, 2016.

[31] A. R. Spencer, A. Primbetova, A. N. Koppes, R. A. Koppes, H. Fenniri, and N. Annabi, "Electroconductive gelatin methacryloyl-PEDOT:pss composite hydrogels: design, synthesis, and properties," ACS Biomaterials Science \& Engineering, vol. 4, pp. 1558-1567, 2018.

[32] S. Wang, S. Guan, Z. Zhu, W. Li, T. Liu, and X. Ma, "Hyaluronic acid doped-poly(3,4-ethylenedioxythiophene)/chitosan/gelatin (PEDOT-HA/Cs/Gel) porous conductive scaffold for nerve regeneration," Materials Science and Engineering: $C$, vol. 71, pp. 308-316, 2017.

[33] Y. Zheng, H. Wang, and Z. Ma, “A nanocomposite containing Prussian Blue, platinum nanoparticles and polyaniline for multi-amplification of the signal of voltammetric immunosensors: highly sensitive detection of carcinoma antigen 125," Microchimica Acta, vol. 184, no. 11, pp. 4269-4277, 2017.

[34] H. Li, S. Pan, P. Xia et al., "Advances in the application of gold nanoparticles in bone tissue engineering," Journal of Biological Engineering, vol. 14, no. 1, 2020.

[35] N. Wang, J. Y. H. Fuh, S. T. Dheen, and A. Senthil Kumar, "Functions and applications of metallic and metallic oxide nanoparticles in orthopedic implants and scaffolds," Journal of Biomedical Materials Research Part B: Applied Biomaterials, vol. 109, no. 2, p. 160, 2020.

[36] S. K. Gulla, B. R. Rao, G. Moku et al., "In vivo targeting of DNA vaccines to dendritic cells using functionalized gold nanoparticles," Biomaterials Science, vol. 7, no. 3, pp. 773-788, 2019.

[37] M. Hernández-Rivera, S. Y. Cho, S. E. Moghaddam et al., "Labeling stem cells with a new hybrid bismuth/carbon nanotube contrast agent for X-ray imaging," Contrast Media \& Molecular Imaging, vol. 2019, p. 1, Article ID 2183051, 2019.

[38] P. Zhang, J. Qin, B. Zhang et al., "Gentamicin-loaded silk/ nanosilver composite scaffolds for MRSA-induced chronic osteomyelitis," Royal Society Open Science, vol. 6, no. 5, Article ID 182102, 2019.

[39] A. Pourjavadi, M. Doroudian, A. Ahadpour, and S. Azari, "Injectable chitosan/ $\kappa$-carrageenan hydrogel designed with au nanoparticles: a conductive scaffold for tissue engineering demands," International Journal of Biological Macromolecules, vol. 126, pp. 310-317, 2019.

[40] B. Maharjan, D. Kumar, G. P. Awasthi et al., "Synthesis and characterization of gold/silica hybrid nanoparticles incorporated gelatin methacrylate conductive hydrogels for $\mathrm{H} 9 \mathrm{C} 2$ cardiac cell compatibility study," Composites Part B: Engineering, vol. 177, Article ID 107415, 2019.

[41] P. Makvandi, G. W. Ali, F. Della Sala, W. I. Abdel-Fattah, and A. Borzacchiello, "Hyaluronic acid/corn silk extract based injectable nanocomposite: a biomimetic antibacterial scaffold for bone tissue regeneration," Materials Science and Engineering: C, vol. 107, Article ID 110195, 2020.

[42] S. I. Basha, S. Ghosh, K. Vinothkumar et al., "Fumaric acid incorporated Ag/agar-agar hybrid hydrogel: a multifunctional 
avenue to tackle wound healing," Materials Science and Engineering: C, vol. 111, Article ID 110743, 2020.

[43] M. Ribeiro, M. P. Ferraz, F. J. Monteiro et al., "Antibacterial silk fibroin/nanohydroxyapatite hydrogels with silver and gold nanoparticles for bone regeneration," Nanomedicine: Nanotechnology, Biology and Medicine, vol. 13, no. 1, pp. 231-239, 2017.

[44] Z. Cao, D. Wang, Y. Li et al., "Effect of nanoheat stimulation mediated by magnetic nanocomposite hydrogel on the osteogenic differentiation of mesenchymal stem cells," Science China Life Sciences, vol. 61, no. 4, pp. 448-456, 2018.

[45] H.-L. Tan, S.-Y. Teow, and J. Pushpamalar, "Application of metal nanoparticle-hydrogel composites in tissue regeneration," Bioengineering, vol. 6, no. 17, 2019.

[46] C. Yi, D. Liu, C.-C. Fong, J. Zhang, and M. Yang, "Gold nanoparticles promote osteogenic differentiation of mesenchymal stem cells through p38 MAPK pathway," ACS Nano, vol. 4, no. 11, pp. 6439-6448, 2010.

[47] H. Qin, C. Zhu, Z. An et al., "Silver nanoparticles promote osteogenic differentiation of human urine-derived stem cells at noncytotoxic concentrations," International Journal of Nanomedicine, vol. 9, pp. 2469-2478, 2014.

[48] S. Homaeigohar, T.-Y. Tsai, T.-H. Young, H. J. Yang, and Y.-R. Ji, "An electroactive alginate hydrogel nanocomposite reinforced by functionalized graphite nanofilaments for neural tissue engineering," Carbohydrate Polymers, vol. 224, Article ID 115112, 2019.

[49] R. Wang, Q. Yu, Y. He et al., "Self-assembled polyelectrolytebased composite hydrogels with enhanced stretchable and adsorption performances," Journal of Molecular Liquids, vol. 294, Article ID 111576, 2019.

[50] S. Talebian, M. Mehrali, R. Raad et al., "Electrically conducting hydrogel graphene nanocomposite biofibers for biomedical applications," Frontiers in Chemistry, vol. 8, 2020.

[51] A. Vashist, A. Kaushik, A. Vashist et al., "Advances in carbon nanotubes-hydrogel hybrids in nanomedicine for therapeutics," Advanced Healthcare Materials, vol. 7, no. 9, Article ID 1701213, 2018.

[52] Y. Liang, X. Zhao, T. Hu, Y. Han, and B. Guo, "Mussel-inspired, antibacterial, conductive, antioxidant, injectable composite hydrogel wound dressing to promote the regeneration of infected skin," Journal of Colloid and Interface Science, vol. 556, pp. 514-528, 2019.

[53] A. C. P. de Vasconcelos, R. P. Morais, G. B. Novais et al., "In situ photocrosslinkable formulation of nanocomposites based on multi-walled carbon nanotubes and formononetin for potential application in spinal cord injury treatment," Nanomedicine: Nanotechnology, Biology and Medicine, vol. 29, Article ID 102272, 2020.

[54] C. Wang, W. Huang, Y. Zhou et al., "3D printing of bone tissue engineering scaffolds," Bioactive Materials, vol. 5, no. 1, pp. 82-91, 2020.

[55] L. Liu, B. Yang, L.-Q. Wang et al., "Biomimetic bone tissue engineering hydrogel scaffolds constructed using ordered CNTs and HA induce the proliferation and differentiation of BMSCs," Journal of Materials Chemistry B, vol. 8, no. 3, pp. 558-567, 2020.

[56] H. Lu, N. Zhang, and M. Ma, "Electroconductive hydrogels for biomedical applications," Wiley Interdisciplinary Reviews: Nanomedicine and Nanobiotechnology, vol. 11, no. 6, p. e1568, 2019.

[57] D. Gan, L. Han, M. Wang et al., "Conductive and tough hydrogels based on biopolymer molecular templates for controlling in situ formation of polypyrrole nanorods," ACS
Applied Materials \& Interfaces, vol. 10, no. 42, pp. 3621836228, 2018.

[58] Y. Liang, B. Chen, M. Li, J. He, Z. Yin, and B. Guo, "Injectable antimicrobial conductive hydrogels for wound disinfection and infectious wound healing," Biomacromolecules, vol. 21, no. 5, pp. 1841-1852, 2020.

[59] J. Qu, X. Zhao, Y. Liang, Y. Xu, P. X. Ma, and B. Guo, "Degradable conductive injectable hydrogels as novel antibacterial, anti-oxidant wound dressings for wound healing," Chemical Engineering Journal, vol. 362, pp. 548-560, 2019.

[60] B. Zhang, J. He, M. Shi, Y. Liang, and B. Guo, "Injectable selfhealing supramolecular hydrogels with conductivity and photo-thermal antibacterial activity to enhance complete skin regeneration," Chemical Engineering Journal, vol. 400, Article ID 125994, 2020.

[61] J. He, M. Shi, Y. Liang, and B. Guo, "Conductive adhesive selfhealing nanocomposite hydrogel wound dressing for photothermal therapy of infected full-thickness skin wounds," Chemical Engineering Journal, vol. 394, Article ID 124888, 2020.

[62] X. Zhao, H. Wu, B. Guo, R. Dong, Y. Qiu, and P. X. Ma, "Antibacterial anti-oxidant electroactive injectable hydrogel as self-healing wound dressing with hemostasis and adhesiveness for cutaneous wound healing," Biomaterials, vol. 122, pp. 34-47, 2017.

[63] J.-O. You, M. Rafat, G. J. C. Ye, and D. T. Auguste, "Nanoengineering the heart: conductive scaffolds enhance connexin 43 expression," Nano Letters, vol. 11, no. 9, pp. 3643-3648, 2011.

[64] W. Zhang, P. Feng, J. Chen, Z. Sun, and B. Zhao, "Electrically conductive hydrogels for flexible energy storage systems," Progress in Polymer Science, vol. 88, pp. 220-240, 2019.

[65] A. R. Short, D. Koralla, A. Deshmukh et al., "Hydrogels that allow and facilitate bone repair, remodeling, and regeneration," Journal of Materials Chemistry B, vol. 3, no. 40, pp. 7818-7830, 2015.

[66] S. Kumar, M. Nehra, D. Kedia, N. Dilbaghi, K. Tankeshwar, and K.-H. Kim, "Nanotechnology-based biomaterials for orthopaedic applications: recent advances and future prospects," Materials Science and Engineering: C, vol. 106, Article ID 110154, 2020.

[67] M. Shahin, K. Munir, C. Wen, and Y. Li, "Magnesium matrix nanocomposites for orthopedic applications: a review from mechanical, corrosion, and biological perspectives," Acta Biomaterialia, vol. 96, pp. 1-19, 2019.

[68] X. Guan, M. Avci-Adali, E. Alarçin et al., "Development of hydrogels for regenerative engineering," Biotechnology Journal, vol. 12, no. 5, Article ID 1600394, 2017.

[69] S. Yang, L. Jang, S. Kim et al., "Polypyrrole/alginate hybrid hydrogels: electrically conductive and soft biomaterials for human mesenchymal stem cell culture and potential neural tissue engineering applications," Macromolecular Bioscience, vol. 16, no. 11, pp. 1653-1661, 2016.

[70] J. Jiang, Y. Huang, Y. Wang, H. Xu, M. Xing, and W. Zhong, "Mussel-inspired dopamine and carbon nanotube leading to a biocompatible self-rolling conductive hydrogel film," Materials, vol. 10, no. 8, p. 964, 2017.

[71] Y. Wang, Y. Xiao, G. Gao et al., "Conductive graphene oxide hydrogels reduced and bridged by l-cysteine to support cell adhesion and growth," Journal of Materials Chemistry B, vol. 5, no. 3, pp. 511-516, 2017.

[72] B. Hermenegildo, C. Ribeiro, L. Pérez-Álvarez et al., "Hydrogel-based magnetoelectric microenvironments for 
tissue stimulation," Colloids and Surfaces B: Biointerfaces, vol. 181, pp. 1041-1047, 2019.

[73] J. Zhang, Y. Sun, Y. Li, and H. Wang, "Consumer health information organising and mobile acquiring based on topic maps," International Journal of Ad Hoc and Ubiquitous Computing, vol. 23, no. 1/2, pp. 46-59, 2016.

[74] M. Eischen-Loges, K. M. C. Oliveira, M. B. Bhavsar, J. H. Barker, and L. Leppik, "Pretreating mesenchymal stem cells with electrical stimulation causes sustained long-lasting pro-osteogenic effects," Peer Journal, vol. 6, p. e4959, 2018.

[75] J. Li, X. Liu, J. M. Crook, and G. G. Wallace, "Electrical stimulation-induced osteogenesis of human adipose derived stem cells using a conductive graphene-cellulose scaffold," Materials Science and Engineering: C, vol. 107, Article ID 110312, 2020.

[76] A. Patel, Y. Xue, R. Hartley et al., "Hierarchically aligned fibrous hydrogel films through microfluidic self-assembly of graphene and polysaccharides," Biotechnology and Bioengineering, vol. 115, no. 10, pp. 2654-2667, 2018.

[77] P. Srisuk, F. V. Berti, L. P. da Silva, A. P. Marques, R. L. Reis, and V. M. Correlo, "Electroactive gellan gum/polyaniline spongy-like hydrogels," ACS Biomaterials Science \& Engineering, vol. 4, pp. 1779-1787, 2018.

[78] M. Zhou, N. Lozano, J. K. Wychowaniec et al., "Graphene oxide: a growth factor delivery carrier to enhance chondrogenic differentiation of human mesenchymal stem cells in 3D hydrogels," Acta Biomaterialia, vol. 96, pp. 271-280, 2019.

[79] N. Shadjou, M. Hasanzadeh, and B. Khalilzadeh, "Graphene based scaffolds on bone tissue engineering," Bioengineered, vol. 9, no. 1, pp. 38-47, 2018.

[80] D. Puppi, C. Migone, L. Grassi et al., "Integrated three-dimensional fiber/hydrogel biphasic scaffolds for periodontal bone tissue engineering," Polymer International, vol. 65, no. 6 , pp. 631-640, 2016.

[81] F. Mohabatpour, A. Karkhaneh, and A. M. Sharifi, "A hydrogel/fiber composite scaffold for chondrocyte encapsulation in cartilage tissue regeneration," RSC Advances, vol. 6, no. 86, pp. 83135-83145, 2016.

[82] S. Khorshidi and A. Karkhaneh, "Hydrogel/fiber conductive scaffold for bone tissue engineering," Journal of Biomedical Materials Research Part A, vol. 106, no. 3, pp. 718-724, 2018.

[83] K. D. McKeon-Fischer, D. H. Flagg, and J. W. Freeman, "Coaxial electrospun poly( $\varepsilon$-caprolactone), multiwalled carbon nanotubes, and polyacrylic acid/polyvinyl alcohol scaffold for skeletal muscle tissue engineering," Journal of Biomedical Materials Research Part A, vol. 99A, no. 3, pp. 493-499, 2011.

[84] B. Guo, J. Qu, X. Zhao, and M. Zhang, "Degradable conductive self-healing hydrogels based on dextran-graft-tetraaniline and $\mathrm{N}$-carboxyethyl chitosan as injectable carriers for myoblast cell therapy and muscle regeneration," Acta Biomaterialia, vol. 84, pp. 180-193, 2019.

[85] K. M. Sajesh, R. Jayakumar, S. V. Nair, and K. P. Chennazhi, "Biocompatible conducting chitosan/polypyrrole-alginate composite scaffold for bone tissue engineering," International Journal of Biological Macromolecules, vol. 62, pp. 465-471, 2013.

[86] X. Xie, K. Hu, D. Fang, L. Shang, S. D. Tran, and M. Cerruti, "Graphene and hydroxyapatite self-assemble into homogeneous, free standing nanocomposite hydrogels for bone tissue engineering," Nanoscale, vol. 7, no. 17, pp. 7992-8002, 2015.

[87] F. Ketabat, A. Karkhaneh, R. Mehdinavaz Aghdam, and S. Hossein Ahmadi Tafti, "Injectable conductive collagen/ alginate/polypyrrole hydrogels as a biocompatible system for biomedical applications," Journal of Biomaterials Science, Polymer Edition, vol. 28, no. 8, pp. 794-805, 2017.

[88] X. Zhao, P. Li, B. Guo, and P. X. Ma, "Antibacterial and conductive injectable hydrogels based on quaternized chitosan-graft-polyaniline/oxidized dextran for tissue engineering," Acta Biomaterialia, vol. 26, pp. 236-248, 2015.

[89] G. Tan, Y. Liu, L. Zhou et al., "Covalent bonding of an electroconductive hydrogel to gold-coated titanium surfaces via thiol-ene click chemistry," Macromolecular Materials and Engineering, vol. 301, no. 12, pp. 1423-1429, 2016.

[90] H. Yuk, T. Zhang, S. Lin, G. A. Parada, and X. Zhao, "Tough bonding of hydrogels to diverse non-porous surfaces," Nature Materials, vol. 15, no. 2, pp. 190-196, 2016.

[91] H. Yuk, B. Lu, and X. Zhao, "Hydrogel bioelectronics," Chemical Society Reviews, vol. 48, no. 6, pp. 1642-1667, 2019.

[92] M. Bansal, A. Dravid, Z. Aqrawe, J. Montgomery, Z. Wu, and D. Svirskis, "Conducting polymer hydrogels for electrically responsive drug delivery," Journal of Controlled Release, vol. 328, pp. 192-209, 2020.

[93] P. Chansai, A. Sirivat, S. Niamlang, D. Chotpattananont, and K. Viravaidya-Pasuwat, "Controlled transdermal iontophoresis of sulfosalicylic acid from polypyrrole/poly(acrylic acid) hydrogel," International Journal of Pharmaceutics, vol. 381, no. 1, pp. 25-33, 2009.

[94] J. Qu, Y. Liang, M. Shi, B. Guo, Y. Gao, and Z. Yin, "Biocompatible conductive hydrogels based on dextran and aniline trimer as electro-responsive drug delivery system for localized drug release," International Journal of Biological Macromolecules, vol. 140, pp. 255-264, 2019.

[95] J. Qu, X. Zhao, P. X. Ma, and B. Guo, "Injectable antibacterial conductive hydrogels with dual response to an electric field and $\mathrm{pH}$ for localized "smart" drug release," Acta Biomaterialia, vol. 72, pp. 55-69, 2018.

[96] S. Qian, Z. Yan, Y. Xu et al., "Carbon nanotubes as electrophysiological building blocks for a bioactive cell scaffold through biological assembly to induce osteogenesis," RSC Advances, vol. 9, no. 21, pp. 12001-12009, 2019.

[97] R. S. L. Aparna, R. G. S. V. Prasad, and N. P. Nirmal, "An injectable in-situ conducting thermosensitive gel for controlled delivery of vancomycin in osteomyelitis treatment and bone regeneration," Science of Advanced Materials, vol. 8, no. 7, pp. 1470-1477, 2016.

[98] S. Nejati, R. Karimi Soflou, S. Khorshidi, and A. Karkhaneh, "Development of an oxygen-releasing electroconductive insitu crosslinkable hydrogel based on oxidized pectin and grafted gelatin for tissue engineering applications," Colloids and Surfaces B: Biointerfaces, vol. 196, Article ID 111347, 2020. 